\title{
Dissecting Resistance to Phytophthora cinnamomi in Interspecific Hybrid Chestnut Crosses Using Sequence-Based Genotyping and QTL Mapping
}

\author{
Tetyana N. Zhebentyayeva, ${ }^{1,2, \dagger}$ Paul H. Sisco, ${ }^{3}$ Laura L. Georgi, ${ }^{3}$ Steven N. Jeffers, ${ }^{4}$ M. Taylor Perkins, ${ }^{5}$ Joseph B. James, ${ }^{6}$ \\ Frederick V. Hebard, ${ }^{3}$ Christopher Saski, ${ }^{4}$ C. Dana Nelson, ${ }^{7,8}$ and Albert G. Abbott ${ }^{8}$ \\ ${ }^{1}$ Department of Ecosystem Science and Management, The Pennsylvania State University, University Park, PA 16802 \\ ${ }^{2}$ Clemson University Genomics and Computational Biology Laboratory, Clemson, SC 29634 \\ ${ }^{3}$ Meadowview Research Farms, The American Chestnut Foundation, Meadowview, VA 24361 \\ ${ }^{4}$ Department of Plant and Environmental Sciences, Clemson University, Clemson, SC 29634 \\ ${ }^{5}$ Department of Biology, Geology, and Environmental Science, University of Tennessee at Chattanooga, Chattanooga, TN 37403 \\ ${ }^{6}$ Chestnut Return Farms, Seneca, SC 29678 \\ ${ }^{7}$ Southern Institute of Forest Genetics, Southern Research Station, U.S. Department of Agriculture Forest Service, Saucier, MS 39574 \\ ${ }^{8}$ Forest Health Research and Education Center, University of Kentucky, Lexington, KY 40546 \\ Accepted for publication 21 April 2019.
}

\begin{abstract}
The soilborne oomycete Phytophthora cinnamomi-which causes root rot, trunk cankers, and stem lesions on an estimated 5,000 plant species worldwide-is a lethal pathogen of American chestnut (Castanea dentata) as well as many other woody plant species. $P$. cinnamomi is particularly damaging to chestnut and chinquapin trees (Castanea spp.) in the southern portion of its native range in the United States due to relatively mild climatic conditions that are conductive to disease development. Introduction of resistant genotypes is the most practical solution for disease management in forests because treatment with fungicides and eradication of the pathogen are neither practical nor economically feasible in natural ecosystems. Using backcross families derived from crosses of American chestnuts with two resistant Chinese chestnut cultivars Mahogany and Nanking, we constructed linkage maps and identified quantitative trait loci (QTLs) for resistance to $P$. cinnamomi that had been introgressed from these Chinese chestnut cultivars. In total, 957 plants representing five cohorts of three hybrid crosses were
\end{abstract}

ABSTRACT

Phytophthora cinnamomi-the oomycete pathogen causing Phytophthora root rot of American chestnut (Castanea dentata) is one of the most devastating plant pathogens worldwide and, in combination with Cryphonectria parasitica - the cause of chestnut blight, contributed to the demise of American chestnut trees in eastern North America. P. cinnamomi has the largest reported host range of any species of the genus Phytophthora, which currently is estimated to be $\sim 5,000$ plant species (Burgess et al. 2017; Erwin and Ribeiro 1996; Hardham and Blackman 2018; Shearer et al. 2007). $P$. cinnamomi occurs on all continents of the world except Antarctica and affects both economically and ecologically important species, including avocado (Stolzy et al. 1967; Wager 1942; Zentmyer 1980), pineapple (Zentmyer 1980), oaks (Jung

\section{${ }^{\dagger}$ Corresponding author: T. N. Zhebentyayeva; tnz4@psu.edu}

Funding: This information is based on research that was supported by the Foundation for Carolinas, The American Chestnut Foundation, the Forest Health Initiative, the U.S. Department of Agriculture (USDA) Forest Service, and the USDA National Institute of Food and Agriculture under project numbers SC1700445, SC-1700481, and SC-1700534 at Clemson University.

*The $\boldsymbol{e}$-Xtra logo stands for "electronic extra" and indicates that one supplementary figures and six supplementary tables are published online.

The author(s) declare no conflict of interest.

(c) 2019 The American Phytopathological Society genotyped by sequencing and phenotyped by standardized inoculation and visual examination over a 6-year period from 2011 to 2016. Eight parental linkage maps comprising 7,715 markers were constructed, and 17 QTLs were identified on four linkage groups (LGs): LG_A, LG_C, LG_E, and LG_K. The most consistent QTLs were detected on LG_E in seedlings from crosses with both 'Mahogany' and 'Nanking' and LG_K in seedlings from 'Mahogany' crosses. Two consistent large and medium effect QTLs located $\sim 10 \mathrm{cM}$ apart were present in the middle and at the lower end of LG_E; other QTLs were considered to have small effects. These results imply that the genetic architecture of resistance to $P$. cinnamomi in Chinese chestnut $\times$ American chestnut hybrid progeny may resemble the $P$. sojae-soybean pathosystem, with a few dominant QTLs along with quantitatively inherited partial resistance conferred by multiple small-effect QTLs.

Keywords: analytical plant pathology, theoretical plant pathology et al. 2018; Tainter et al. 2000), eucalyptus (Podger et al. 1965), and many woody ornamental plants (Duan et al. 2008; Olson et al. 2013; Zentmyer 1980).

Considering the importance of $P$. cinnamomi as a pathogen that attacks a broad range of woody plant species in many different families and the substantial knowledge of disease development on susceptible plants (reviewed by Hardham and Blackman 2018; Oßwald et al. 2014; Zentmyer 1980), we know much less about plant resistance to this pathogen compared with that of the more well-studied diseases caused by Phytophthora spp. on agricultural crops, such as potato ( $P$. infestans) and soybean ( $P$. sojae). What is known about resistance to this disease in woody plants is based on work in several important species: eucalyptus (Cahill and McComb 1992; Cahill et al. 1989; Dempsey et al. 2012; Stukely and Crane 1994), oaks (Coelho et al. 2011; Ebadzad and Cravador 2014), avocado (Engelbrecht and van den Berg 2013; Mahomed and van den Berg 2011; Reeksting et al. 2014), and chestnut (Kubisiak 2010; Santos et al. 2015, 2017a, b; Serrazina et al. 2015). Much of this prior work correlates specific gene transcripts or physiological products with resistance or susceptibility but lacks a direct causal genetic link of the resistance phenotype to specific differentially expressed genes. Fortunately, the genus Castanea encompasses both resistant and susceptible species, with weak reproductive barriers enabling development of hybrid populations segregating for resistance and suitable for genetic analyses. This approach provides the needed genetic link to prioritize candidate genes that 
show expression differences and are located in genomic regions conferring resistance.

The relatively mild climatic conditions in the southeastern United States are favorable to active growth and survival of $P$. cinnamomi, and, therefore, are conducive to disease development by this soilborne plant pathogen. Consequently, P. cinnamomi contributed to the elimination of chestnut from the Piedmont physiographic region 40 to 75 years before chestnut blight was reported in North America (Anagnostakis 2012; Freinkel 2007; Jacobs et al. 2013; Russell 1987). Substantial levels of resistance to both $P$. cinnamomi and $C$. parasitica have been found in Asian species of the genus Castanea - particularly in Chinese chestnut (Castanea mollissima) and Japanese chestnut (Castanea crenata) (Anagnostakis 1992, 2012; Crandall et al. 1945; Graves 1950). The American Chestnut Foundation (TACF) and others in the forest genetics community have pursued backcross (BC) breeding programs to introgress resistance to $C$. parasitica and $P$. cinnamomi from Chinese and Japanese chestnut into American chestnut (Anagnostakis 2012; Burnham 1988; Steiner et al. 2017). For pyramiding resistance to both pathogens, the hybrid chestnut families selected for resistance to $C$. parasitica are being evaluated for resistance to $P$. cinnamomi. An effective protocol for screening for resistance to $P$. cinnamomi based on severity of root rot symptoms has been developed and implemented in breeding efforts (Jeffers et al. 2009; Westbrook et al. 2019). These hybrid chestnut families and disease screening tools provide the material and means to determine the genetic architecture of resistance to $P$. cinnamomi in chestnut. Indeed, a preliminary quantitative trait locus (QTL) mapping study with a limited number of progeny from an interspecific $C$. dentata $\times$ C. mollissima cross in $\mathrm{BC}_{1}$ configuration identified a significant QTL for resistance to $P$. cinnamomi on linkage group E (LG_E) (Kubisiak 2010). However, the sparse marker density and low progeny numbers significantly impacted the QTL resolution at the genome scale. Researchers in Portugal using families segregating for resistance from a cross of susceptible European chestnut (Castanea sativa) with resistant Japanese chestnut also constructed a low-resolution genetic map and found a QTL for resistance on LG_E as well as one on LG_K (Santos et al. 2017b).

The advent of next generation sequencing revolutionized discovery, validation, and assessment of genetic markers in natural and hybrid populations. In combination with whole-genome sequencing, one of its modifications, restriction site-associated DNA sequencing, provides an efficient and inexpensive tool to discover single-nucleotide polymorphisms (SNPs) in nonmodel species. SNPs enable genome-wide association studies and mapping of QTLs in biparental populations (reviewed by Davey et al. 2011; Ganal et al. 2014; Jamann et al. 2015; Parchman et al. 2018). Using this genotype-by-sequencing (GBS) approach, saturated linkage maps were constructed to identify QTLs for important traits in several perennial woody species: for example, resistance to powdery mildew and foliar phylloxera in grape (Clark et al. 2018; Teh et al. 2017), blue mold and fire blight in apple (Desnoues et al. 2018; Norelli et al. 2017), and plant height variation in poplar (Zhigunov et al. 2017). Sequence-based genetic maps were also generated for a variety of traits in other forest species-such as northern red oak (Konar et al. 2017), poplar (Mousavi et al. 2016; Schilling et al. 2014), and oil palm (Bai et al. 2018).

In this paper, we report the use of GBS on five cohorts of three interspecific hybrid chestnut crosses derived from two Chinese chestnut sources of resistance to $P$. cinnamomi, cultivars Mahogany and Nanking. We used traditional linkage mapping and QTL analyses to delineate genetic intervals underlying resistance to P. cinnamomi to determine (i) how many potential genomic regions (i.e., QTLs) control resistance to $P$. cinnamomi in interspecific hybrids between Chinese and American chestnut genotypes, (ii) the extent of colocalization of genomic regions governing resistance introgressed from different Chinese chestnut sources, and (iii) the stability of QTLs over years under varying environmental conditions. Results of this study will facilitate additional development of genetic markers for breeding programs being conducted by TACF and other organizations aimed at incorporating resistance to $P$. cinnamomi into advanced chestnut progenies selected for resistance to $C$. parasitica. Additionally, comparing genome sequences of American and Chinese chestnut within the QTL intervals reported here will assist in discovering candidate genes through integration of QTL data with ongoing RNA sequencing (RNA-seq) and metabolomics studies of $P$. cinnamomi-resistant and susceptible plants.

\section{MATERIALS AND METHODS}

Mapping populations. Plants for this study were produced by controlled pollination at three TACF locations: two Carolinas Chapter sites (one in North Carolina and one in South Carolina) and the Meadowview Research Farms in Virginia (Table 1). Three crosses were used that belonged to the $\mathrm{BC}_{1} \mathrm{~F}_{1}$ and $\mathrm{BC}_{3} \mathrm{~F}_{1}$ generations. The first cross $\mathrm{HB} 2$ - carrying resistance from the Chinese chestnut 'Mahogany', was obtained by crossing the Chinese/American $\mathrm{F}_{1}$ hybrid $\mathrm{KY} 115\left(\mathrm{RCF}_{1} \times\right.$ 'Mahogany') at Meadowview Research Farms with pollen from the American tree AD98. The second cross, NK4, originated by pollinating flowers of an $F_{1}$ American/Chinese tree CG61 located in Landrum, South Carolina with pollen from the American chestnut tree NCDOT from Asheville, North Carolina. The parent CG61 was derived from a cross of the American chestnut tree Ted Farmer A (North Carolina origin) with tree GR119, which was a Meadowview ramet of the resistant cultivar Nanking (Meadowview Research Farms). Finally, the third cross, JB1, was derived from crossing the American chestnut tree cultivar Cranberry (North Carolina origin) with pollen from JB197, a $\mathrm{BC}_{2} \mathrm{~F}_{1}$ hybrid (Meadowview Research Farms) that putatively carried resistance derived from 'Mahogany' via the $\mathrm{F}_{1}$ hybrid SpR4T52 (located at the Connecticut Agricultural Experiment Station). The crosses HB2 and JB1 were each repeated in a second year, yielding a total of five cohorts of the three crosses. The four-digit numbers following the name of the cross reflect the year that seedlings were phenotyped (e.g., HB2-2013 and HB2-2014 belong to the same seed progeny generated in 2012 and 2013, respectively, and evaluated in 2013 and 2014, respectively). In this paper, family refers to all seedlings from a given cross.

Phenotyping. Seedlings were grown and evaluated at Chestnut Return Farms in Seneca, South Carolina, and phenotyping for root rot severity was conducted at the end of each growing season following a standard protocol (Jeffers et al. 2009). This project was conducted from 2011 to 2016 as part of and fully integrated with a 14-year study to evaluate hybrid American chestnut seedlings for resistance to P. cinnamomi (Westbrook et al. 2019). Briefly, in April, stratified seeds were planted outside in 568-liter plastic tubs (Rubbermaid Structural Foam Stock Tank FG424500) containing a soilless peat and bark container mix (Fafard 3B Mix; currently produced by Sun Gro Horticulture) using a randomized block planting design, where each tub was a block. American (susceptible) and Chinese (resistant) chestnut seedling controls were included in each tub. In July, roots of 13- to 15-week-old seedlings were inoculated with a mixture of two isolates of $P$. cinnamomi previously recovered from diseased chestnut trees at the study site. Evaluation of disease severity was based on visual examination of the roots of individual seedlings in December or January after plants were dormant and about 8 to 9 months old (i.e., 5 to 6 months after inoculation). Four symptom severity classes were recognized: class 0 , roots healthy and no evidence of infection; class 1 , root rot symptoms on any of the feeder roots; class 2 , root rot symptoms on the tap root or severe root rot on the feeder roots; and class 3, seedling dead and all roots are rotted (Jeffers et al. 2009). The typical appearance of phenotype classes is shown in Supplementary Figure S1. Progeny of the JB1-2013 cross were grown and 
phenotyped in Pegram, Tennessee following the same protocol used in South Carolina, but seedlings were inoculated with an isolate of P. cinnamomi recovered from a chestnut orchard in Lincoln County, Tennessee.

DNA extraction and short-reads library preparation. Each year, young leaves on seedlings for genetic analysis were collected before inoculation, and DNA was extracted using a CTAB method as described by Kubisiak et al. (2013). Genomic DNA was quantified using either the Qubit quantitation assay (Thermo Fisher Scientific) or the QuantiFluor dsDNA system (Promega Corp.) in combination with a Synergy H1 microplate reader (BioTek Instruments, Inc.). DNA integrity was checked on a $1 \%$ agarose gel. Restriction site-associated libraries were prepared as described by Elshire et al. (2011) with a few modifications. Briefly, $150 \mathrm{ng}$ of DNA was double digested with Pst 1 and Msp 1 followed by ligation of barcoded adapters compatible with restriction sites. Pools of 48 samples (two pools per 96-well plate) were purified using the QIAquick PCR purification kit (Qiagen Inc.). Verifications of size selection, quantification, and library quality were done as described by Zhebentyayeva et al. (2019). Amplified libraries were pair-end sequenced $(2 \times 125$-bp reads $)$ on a single lane of the Illumina HiSeq 2500 instrument at the Hollings Cancer Center, Medical University of South Carolina in Charleston, South Carolina. Parental genotypes sequenced five or six times in different plates were used as intra- and interplate controls of sequencing quality.

Data processing and SNP discovery. Data processing and SNP genotyping were performed with Stacks v.1.43-v.1.45 (Catchen et al. 2011). Briefly, fastq files with raw paired-end data were demultiplexed, cleaned up of barcodes/adapters, and checked for presence of Pst 1 and Msp 1 restriction sites. The proportion of retained reads was in the range of 95 to $97 \%$, indicating a high quality of raw sequencing data. Individuals with $<0.8$ to 1 million reads were excluded from additional processing. Using GSNAP software (Wu and Nacu 2010), reads were aligned to the reference C. mollissima genome v. 1.1 (https://www.hardwoodgenomics.org/ Genome-assembly/1962958). A catalog of tags and SNP genotypes was generated using a "ref_map" command and encoded as an $\mathrm{F}_{1}$ segregating population type. Replicated parental reads were combined, providing saturated frameworks for SNP genotyping. Genotypes were further filtered for minimum stack depth of five (-m) and a minimum number of genotyped progenies at $90 \%$ necessary to retain any SNP locus (-r). Data were exported from Stacks in a JoinMap format.

Linkage analyses and QTL detection. Two parental maps for each cross (including both cohorts, 2013 and 2014, separately of the HB2 cross) were constructed following a pseudotest cross strategy (Grattapaglia and Sederoff 1994). An input file generated by Stacks was manually curated, and only markers in the $<$ abxcd $>$, $<$ lmxll $>$, and < nnxnp $>$ configurations were imported into JoinMap4.1 under the cross-pollinated population type (Van Ooijen 2006). The dataset was further curated to identify and remove identical individuals (owing to seeds with multiple sprouts) and to exclude monomorphic, high segregation-distorted markers $(P \leq$ 0.05 ) and identical loci (similarity was $>0.95$ ). Individuals with $>30 \%$ of missing data were considered as outcrosses and also removed from the datasets. Markers were assigned to $12 \mathrm{LGs}$ at a logarithm of odds (LOD) score of $>7.0$. Marker orders within LGs were calculated with the regression mapping algorithm and Kosambi functions at default parameters (maximum recombination frequency of 0.4 , minimum LOD of 1.0, and goodness-of-fit jump threshold for removing loci of 5.0). Map graphics were generated with MapChart v. 3.0 (Voorrips 2002). Composite maps were constructed for resistant and susceptible parental maps separately using the LPmerge software in R (Endelman and Plomion 2014).

LGs were assigned and oriented against the Chinese chestnut map of Kubisiak et al. (2013) using markers anchored to C. mollissima v. 1.1 scaffolds as follows. Genomic sequences of the expressed sequence tag (EST)-based simple sequence repeats (SSRs) and SNP markers from the reference map (Kubisiak et al. 2013) were aligned against the $C$. mollissima v. 1.1 scaffolds using in-house script. Scaffold information for the mapped markers on our maps was retrieved from a catalog of tags generated by Stacks. Finally, using a VLOOKUP function in Microsoft Excel, marker positioning in our parental maps was compared with that in the reference map. Misoriented LGs were inverted using JoinMap 4.1.

A QTL analysis was performed using multiple statistical analyses implemented in MapQTL6 (Van Ooijen 2009): that is, nonparametric Kruskal-Wallis test, interval mapping, and multiple quantitative trait locus mapping (MQM). The minimum LOD score for QTL detection was determined by the genome-wide LOD significance threshold $(\alpha=$ 0.05) calculated using 1,000 permutations (Churchill and Doerge 1994). The threshold for declaring QTLs was set at LOD 2.8 in all crosses except HB2-2103, in which individual LOD thresholds of 1.9 and 1.8 were established for LG_E and LG_K, respectively. QTL (q) names reflected the trait (i.e., resistance to $P$. cinnamomi) and their order on the integrated linkage maps LG_E and LG_K, and they were appended with a cross identifier and cohort year. For example, the QTL named qPcE.1-H2013 was the first for P. cinnamomi resistance on LG_E from the 2013 cohort of cross HB2.

Statistical analyses in this study were done with StatPlus:mac package (AnalystSoft Inc.) and EpiTools epidemiological calculators (Sergeant 2018) (http://epitools.ausvet.com.au/content.php? page=home) following recommendation on categorical data analyses (Xu et al. 2010) (http://burdine-stat.princeton.edu/).

\section{RESULTS}

Sequence-based genotyping. A total of 8.7 billion Illumina reads were generated for five cohorts of three hybrid crosses in this study (Table 1 and Supplementary Table S1); $>94 \%$ of the reads passed quality checks and were retained for genotyping. The average number of clean reads for each individual was 7.1 to 10.6 million depending on the cross. Catalogues of sequenced tags generated as reference for SNP discovery contained 80,000 to 112,000 markers. The total number of loci written into unfiltered mapping files was 26,047 SNPs, and the number of SNPs genotyped in $>90 \%$ of the progeny varied from 3,641 in the HB2-2014 dataset to 9,510 SNPs in the combined JB1-2013, 2014 dataset. These genotypes of the five cohorts were exported from Stacks for additional processing and constructing genetic maps.

TABLE 1. Data processing and genotyping statistics for five cohorts of three hybrid chestnut crosses: HB2, JB1, and NK4

\begin{tabular}{|c|c|c|c|c|c|c|c|c|}
\hline Cross-year ${ }^{\mathrm{a}}$ & $\begin{array}{l}\text { Total reads } \\
\text { (million) }\end{array}$ & $\begin{array}{l}\text { Retained reads } \\
\quad \text { (million) }\end{array}$ & $\begin{array}{l}\text { Retained } \\
\text { reads }(\%)\end{array}$ & $\begin{array}{l}\text { Reads per sample } \\
\text { (million) }\end{array}$ & $\begin{array}{l}\text { Stacks depth } \\
(\times)^{\mathrm{b}}\end{array}$ & $\begin{array}{c}\text { Tags in catalog } \\
(\text { no. })^{c}\end{array}$ & $\begin{array}{l}\text { Unfiltered } \\
\text { SNPs (no.) }\end{array}$ & $\begin{array}{c}\text { Loci in } \\
\text { JoinMap (no.) }\end{array}$ \\
\hline HB2-2013 & $1,724.1$ & $1,706.8$ & 98.99 & 10.6 & 117 & 112,240 & 41,470 & 3,976 \\
\hline HB2-2014 & $1,788.4$ & $1,698.7$ & 94.98 & 7.1 & 150 & 82,662 & 19,666 & 3,641 \\
\hline JB1-2013, 2014 & $2,276.5$ & $2,252.6$ & 98.94 & 8.4 & 166 & 104,270 & 18,553 & 9,631 \\
\hline NK4-2014 & $2,924.5$ & $2,902.5$ & 99.23 & 9.4 & 168 & 82,256 & 23,116 & 9,510 \\
\hline Average & $8,713.5$ & $8,560.6$ & 98.00 & 8.9 & 150 & 95,357 & 26,047 & 6,690 \\
\hline
\end{tabular}

a Designation of a specific cross and the year that progeny were phenotyped.

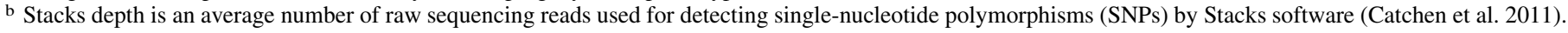

c Tags in catalog are parental single-nucleotide loci genotyped in all individuals in a cross (unfiltered genotypic dataset). 
Linkage map construction and map orientation. Female and male parental maps were constructed for the four datasets (representing three crosses in five cohorts) generated from segregating populations (Table 2 and Supplementary Table S2). Shared parental maps were constructed for the combined cohorts JB1-2013 and JB1-2014 (264 individuals in total), because they were genotyped in the same sequencing run whereas separate maps were made for the HB2-2013 and HB2-2014 cohort genotyped on separate runs. The cohort NK4-2014 was also mapped separately. After removing identical individuals, outcrosses, and individuals with $>30 \%$ missing markers, the number of plants retained for mapping varied from 79 in the JB1-2013 cohort to 302 in the NK42014 cohort. Cumulatively in this study, genotypic data of 957 individuals in three crosses were used in making linkage maps. A total of 22,671 SNPs retained after filtering were assessed for segregation distortion using $\chi^{2}$ goodness-of-fit tests in JoinMap4.1. A total of 7,715 nondistorted SNPs in all parental maps (Table 2) were organized in 12 LGs. The proportion of ungrouped markers (one to five SNPs per map) was low, reflecting the accuracy of the SNP-genotyping pipeline. The resultant genetic maps spanned a total length ranging from 581.2 to $732.0 \mathrm{cM}$ in the KY115-2014 and Cranberry-2013, 2014 maps, respectively. On average, total map length was $657.2 \mathrm{cM}$, with an average marker density of one SNP per 0.86 cM. The largest LG (LG_A for Cranberry-2013, 2014) was composed of 191 markers and spanned $93.22 \mathrm{cM}$ whereas the shortest one (LG_I for KY115-2014) was composed of five markers and spanned $15.10 \mathrm{cM}$ (Supplementary Table S3). Overall, marker order on all groups was in agreement with the reference Chinese chestnut map. Random discrepancies between our maps and the reference were found for only 25 SNPs. Of these, positioning of 16 markers was consistent across our parental maps, possibly indicating misplacement on the reference map.

Among the maps, the only discordant genetic region containing more than five successively mapped SNPs in inverted order was found in the positioning of markers from jb38744 $(43.3 \mathrm{cM})$ to jb72866 (49.9 cM) on LG_E of the JB197-2013, 2014 map compared with the positioning of respective markers on the Cranberry-2013, 2014 map (Fig. 1). On the Chinese chestnut reference map, this interval is flanked by two markers colocalized at $31.5 \mathrm{cM}$ (CmSNP00166, scaffold00766 and CmSNP00540, scaffold04299) and one marker at $47.5 \mathrm{cM}$ (CmSNP01143, scaffold01744). Linkage analysis using two rounds of regression mapping with nondistorted SNPs as well as the maximum likelihood mapping procedure with distorted markers $(P \leq$ 0.005) supported the discordant LG_E region on the JB197-2013, 2014 map (data not shown).

Phenotypic evaluation for resistance to $P$. cinnamomi. In 2011 to 2016, seven hybrid crosses represented by 14 cohorts $(1,895$ individuals) were generated from two Chinese chestnut sources of resistance to P. cinnamomi: 'Mahogany' and 'Nanking'. The complete phenotypic dataset is available in Supplementary Table S4, and it additionally lists the proportional distribution of plants in each phenotypic class and their upper and lower $95 \%$ confidence limits. The proportional distribution was established using Wilson score intervals, and these were class $0,1.1 \%$; class $1,11.0 \%$; class 2 , $45.3 \%$; and class $3,42.6 \%$.

Five cohorts from three extended crosses (957 individuals) phenotyped in multiple years were chosen for sequence-based genotyping (Table 3). Hybrid cohorts HB2-2013, JB1-2013, and JB1-2014 had a high proportion of missing genotypic data caused by low-quality DNA; however, we generated contingency tables and applied Pearson's $\chi^{2}$ test (at the $95 \%$ confidence level) to confirm that individuals with missing genotypic data were randomly excluded and did not significantly impact segregation for resistance (Table 3). To explore further the phenotypic distribution among crosses with different genetic backgrounds phenotyped in multiple years, we performed a $\chi^{2}$ test for independence of phenotypic segregation ratios between cohortyear pairs. The proportion of segregants in each phenotypic class was similar only in two of the unrelated datasets, JB1-2013 and NK4-2014 $\left(\chi^{2}=5.99, P=0.11\right)$. Performance of other hybrid cohorts was not uniform and depended on the cross and the year of phenotyping. To simplify the visual representation, we combined the phenotypic classes 0 and 1 to produce a composite group consisting of the healthiest plants with the least amount of root rot. A ternary diagram reflecting three phenotypic categories $(0+1,2$, and 3 ) and Wilson's confidence intervals agreed with results of a $\chi^{2}$ test for independence (Fig. 2). Proportional distribution for progeny in the different phenotypic classes for the NK4-2014 cross followed that for the combined phenotypic data of the genotyped dataset of 957 plants $\left(\chi^{2}=5.72, P=0.13\right)$. Additionally, a logistic regression analysis identified a main effect of cohort-year on the phenotypic segregation within a cohort, but no effect was found for missing data or cohort-year/missing data interaction (data not shown).

QTL mapping for resistance to $P$. cinnamomi. Using eight parental genetic maps, we conducted a Kruskal-Wallis nonparametric test, interval mapping, and MQM to detect significant marker-trait associations and find cofactors (i.e., markers most associated with resistance to $P$. cinnamomi) (Table 4 and Supplementary Table S5). All three analytical approaches were consistent in detecting significant QTL signals. In all, 17 QTLs were identified using the eight parental maps. Of these, QTLs qPcA.1-H2014 and qPcC.1-N2014 were statistically significant on the maps for the resistant parents KY115 (HB2-2014 cohort) and CG61 (NK4-2014 cohort). Also, a QTL associated with a negative phenotypic effect was detected on LG_A in susceptible parent AD98 (the HB2-2014 dataset).

Two LGs, LG_E and LG_K, were most consistently associated with QTL signals. In the KY $115 \times$ AD98 cross, a QTL signal on LG_K was significant in 2 consecutive years but in slightly different map positions. In 2013, the SNP h31744 at $28.6 \mathrm{cM}$ (LOD 2.5) was

TABLE 2. Summary statistics of genetic maps constructed for the progenies from HB2, JB1, and NK4 crosses used for detection of quantitative trait loci for resistance to Phytophthora cinnamomi

\begin{tabular}{|c|c|c|c|c|c|c|c|}
\hline \multirow[b]{2}{*}{ Cross-year ${ }^{\mathrm{a}}$} & \multirow[b]{2}{*}{ Hybrid type ${ }^{b}$} & \multirow[b]{2}{*}{ Progeny (no.) } & \multirow[b]{2}{*}{ Map designation } & \multicolumn{2}{|c|}{$\mathrm{SNPs}^{\mathrm{c}}$} & \multicolumn{2}{|c|}{ Linkage genetic maps } \\
\hline & & & & Total (no.) & Mapped (no.) & Length (cM) & Density (cM per SNP) \\
\hline \multirow[t]{2}{*}{ HB2-2013 } & \multirow[t]{2}{*}{$\mathrm{BC}_{1}$} & \multirow[t]{2}{*}{156} & KY115-2013 & 2,324 & 972 & 711.0 & 0.73 \\
\hline & & & AD98-2013 & 549 & 352 & 627.9 & 1.78 \\
\hline \multirow[t]{2}{*}{ HB2-2014 } & \multirow[t]{2}{*}{$\mathrm{BC}_{1}$} & \multirow[t]{2}{*}{235} & KY115-2014 & 2,693 & 626 & 581.2 & 0.93 \\
\hline & & & AD98-2014 & 605 & 492 & 690.6 & 1.40 \\
\hline \multirow[t]{2}{*}{ JB1-2013, 2014} & \multirow[t]{2}{*}{$\mathrm{BC}_{3}$} & \multirow[t]{2}{*}{264} & Cranberry-2013, 2014 & 4,126 & 1,380 & 732.0 & 0.53 \\
\hline & & & JB197-2013, 2014 & 2,573 & 1,467 & 668.7 & 0.46 \\
\hline \multirow[t]{2}{*}{ NK4-2014 } & \multirow[t]{2}{*}{$\mathrm{BC}_{1}$} & \multirow[t]{2}{*}{302} & CG61-2014 & 7,027 & 1,184 & 598.2 & 0.51 \\
\hline & & & NCDOT-2014 & 2,774 & 1,242 & 648.4 & 0.52 \\
\hline Total & & 957 & & 22,671 & 7,715 & 657.2 & 0.86 \\
\hline
\end{tabular}

a Designation of a specific cross and the year that progeny were phenotyped.

b Backcross (BC) hybrid generation type.

c SNP, single-nucleotide polymorphism. 
the most significant association in the QTL interval. In 2014, two SNPs, hb7814 and hb27105, were the most associated markers with QTLs at $19.1 \mathrm{cM}$ (LOD 5.1) and $34.5 \mathrm{cM}$ (LOD 4.7), respectively. No significant QTLs on LG_K were detected in the NK4-2014 cohort. However, two potential regions colocalized with qPcK.1 and $\mathrm{qPcK} .2$ in the HB2-2014 cohort were associated with P. cinnamomi resistance, but they were below the threshold level for declaring QTLs. On LG_E, resistance to P. cinnamomi was mapped most consistently from year to year and from cross to cross. The number of most associated markers on LG_E varied from one in the KY115-2014 map (18.2 cM, LOD 4.0) to three in the CG612014 map $(9.1,25.4$, and $47.0 \mathrm{cM}$ with LOD 2.1, 5.0, and 7.2, respectively). The strongest association with resistance was detected in the second half (between 45.1 and $55.4 \mathrm{cM}$ ) of LG_E in

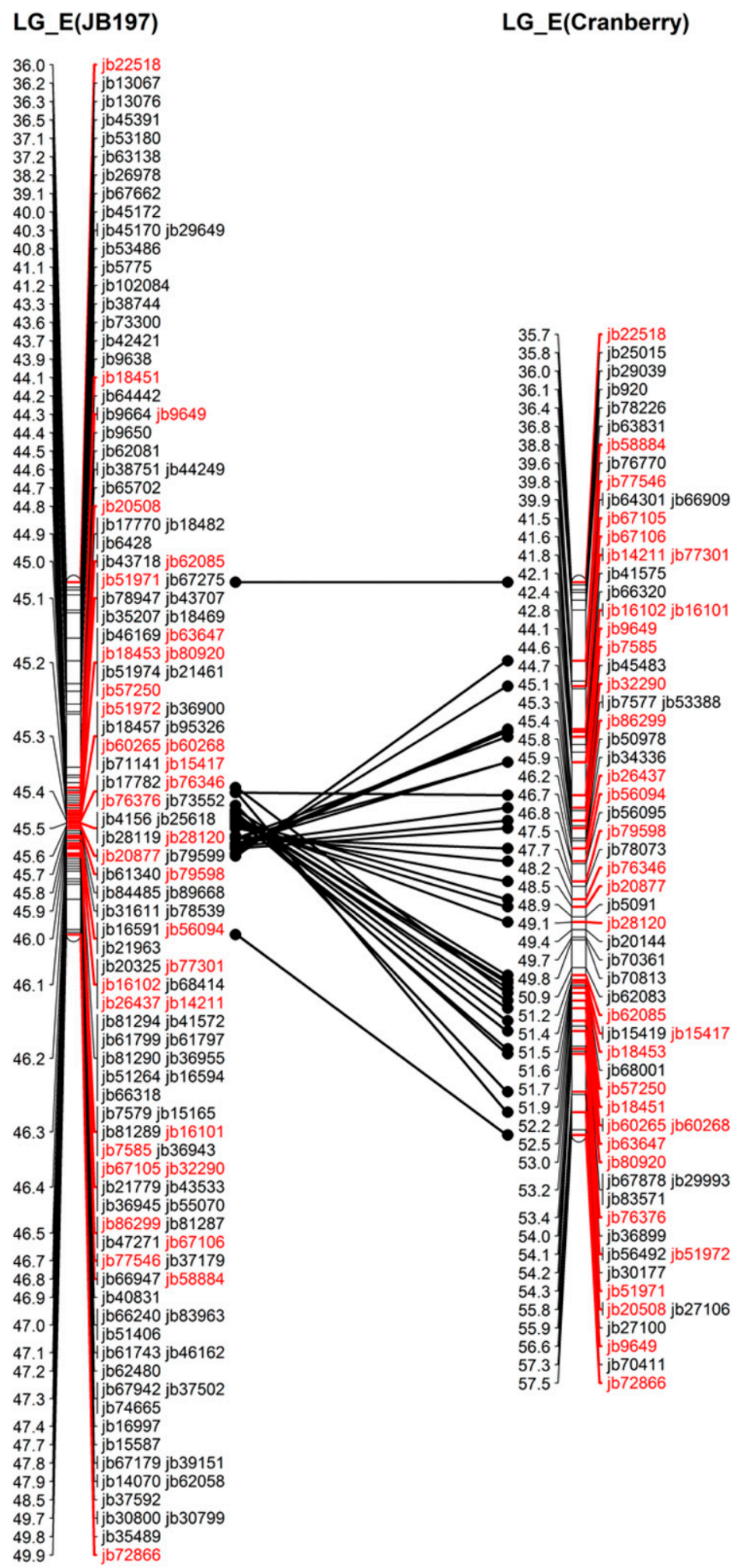

Fig. 1. Fragment of linkage group E (LG_E) for parental maps JB197-2013, 2014 and Cranberry-2013, 2014. Shared markers between maps are highlighted in red. Parental maps were constructed from single-nucleotide polymorphism markers and 264 backcross $3\left(\mathrm{BC}_{3}\right)$ individuals derived from a cross between JB197, a resistant Chinese chestnut (a putatively cultivar Mahogany-derived $\mathrm{BC}_{2}$ hybrid), and an American chestnut tree cultivar Cranberry. A fragment of the map shows genomic regions with discordant markers on the JB197 map. The quantitative trait loci qPcE.2-J2013 and qPcE.2-J2014 are located in this region. 
the JB1 cross phenotyped in 2013 and 2014 in two different locations: Pegram, Tennessee and Seneca, South Carolina, respectively). The two most associated SNPs within QTLs were located at $45.6 \mathrm{cM}$ (LOD 8.7) and $54.0 \mathrm{cM}$ (LOD 16.9) in the JB12013 dataset and at $45.2 \mathrm{cM}$ (LOD 7.8) and $54.6 \mathrm{cM}$ (LOD 12.1) in the JB1-2014 dataset. Possibly because of the advanced degree of backcrossing $\left(\mathrm{BC}_{3}\right)$ and probable fixation of interspecific allelic variation across most LGs, the amount of phenotypic variation explained by qPcE. 2 and qPcE. 3 in JB1 progeny was high-39.1 and $61.7 \%$, respectively, in 2013 and 17.8 and $26.2 \%$, respectively, in 2014. In comparison, most of the QTLs in $\mathrm{BC}_{1}$ populations explained 5 to $12 \%$ of phenotypic variance.

Composite linkage maps and colocalizing QTLs. We merged all five LG_E maps for hybrid parents KY115, JB197, and CG61 and two LG_K maps for the hybrid parent KY115. Anchor markers were identified by assignment of SNPs to C. mollissima v. 1.1 scaffolds. The positions of SNPs within scaffolds were ignored to maximize a number of anchor points. This approximation did not significantly affect marker order on the integrated maps because of the small average size of scaffolds $(<50 \mathrm{~kb})$. Composite LG_E and LG_K maps consisted of 424 and 124 loci and covered 60.72 and $60.12 \mathrm{cM}$, respectively, with a marker density of one SNP per 0.14 and $0.49 \mathrm{cM}$, respectively.

Composite maps were used to address whether QTLs colocalize in multiple years in the different crosses reported in Table 4 (flanking markers are in Supplementary Table S6). For this, we exported tables from MQM results and extracted markers flanking the associated QTLs on the different maps and all markers within intervals. Using marker information, individual QTL intervals and cofactors were delineated on composite maps (Fig. 3). Overlapping QTLs on LG_E were found in three distinct locations in intervals 17.5 to $23.9 \mathrm{cM}$ (qPcE.1), 29.4 to $33.7 \mathrm{cM}$ (qPcE.2), and 49.8 to 59.6 $\mathrm{cM}$ (qPcE.3). Within the first interval, three overlapping weak QTL signals were detected in three crosses: HB2-2013 (LOD 2.1), JB12014 (LOD 2.8), and NK4-2014 (LOD 2.3). The most consistent QTL in all five crosses resided within the second interval. Depending on the cross and the year of phenotyping, LOD for this QTL varied from 2.4 in the HB2-2013 dataset to 9.3 in the JB2-2013 dataset. It is noteworthy that the most associated SSR, CmSI0908 on LG_E in the HB2-2012 cohort, also resided within this interval (Zhebentyayeva et al. 2014). Finally, in the third interval, three consistent QTL signals were detected at the end of LG_E in the JB1-2013, JB1-2014, and NK4-2014 cohorts (LOD 16.9, 12.1, and 3.5, respectively). On composite LG_E, this region was flanked by markers jb32341 at $49.75 \mathrm{cM}$ and nk8101 at $59.63 \mathrm{cM}$.

In the composite LG_K map, three significant associations with resistance to $P$. cinnamomi were found in the $\mathrm{HB} 2$ cross phenotyped in 2013 and 2014. In the HB2-2013 dataset, the most associated

TABLE 3. Phytophthora cinnamomi resistance statistics for genotyped progenies in this study and results from $\chi^{2}$ tests for independence between genotyped and phenotyped datasets

\begin{tabular}{|c|c|c|c|c|c|c|c|}
\hline \multirow[b]{3}{*}{ Cross-year $^{\mathrm{a}}$} & \multicolumn{5}{|c|}{ No. of plants } & & \\
\hline & \multirow[b]{2}{*}{ Total (no.) } & \multicolumn{4}{|c|}{ Root rot severity class ${ }^{b}$} & \multicolumn{2}{|c|}{$\chi^{2}$ test $^{\mathrm{c}}$} \\
\hline & & 0 & 1 & 2 & 3 & $\chi^{2}$ & $P$ value \\
\hline HB2-2013 & 156 & 0 & 8 & 105 & 43 & 1.2562 & 0.5336 \\
\hline HB2-2014 & 235 & 0 & 1 & 106 & 128 & 0.9915 & 0.6091 \\
\hline JB1-2013 & 79 & 2 & 14 & 30 & 33 & 0.9757 & 0.6019 \\
\hline JB1-2014 & 185 & 1 & 4 & 53 & 127 & 0.0567 & 0.9720 \\
\hline NK4-2014 & 302 & 2 & 27 & 118 & 155 & 0.0032 & 0.9984 \\
\hline Total & 957 & 5 & 54 & 412 & 486 & & \\
\hline
\end{tabular}

a Designation of a specific cross and the year that progeny were phenotyped.

${ }^{\mathrm{b}}$ Four root rot severity classes were recognized: 0 , roots healthy; 1 , root rot on feeder roots; 2 , root rot on the tap root or severe root rot on the feeder roots; and 3, all roots rotted and seedling is dead.

c Phenotypic classes 0 and 1 were combined for $\chi^{2}$ tests. marker, h31744, was at $28.6 \mathrm{cM}$ (LOD 2.5). Two nonoverlapping signals in the HB2-2014 map were associated with hb7814 (at 15.8 to $18.3 \mathrm{cM}$, LOD 5.1) and hb27106 (at 28.1 to $34.5 \mathrm{cM}$, LOD 4.3). The three LG_K QTLs qPcK.1-H2013, qPcK.1-H2014, and qPcK.2-H2014 explain 6.7, 9.3, and 7.7\% of phenotypic variation, respectively.

Availability of data and materials. The C. mollissima $\times$ $C$. dentata sequences associated with mapped SNPs and assigned to $C$. mollissima genome scaffolds v. 1.1 are included in the supplementary material for this manuscript. Individual demultiplexed restriction site-associated sequences containing the mapped SNPs are deposited in the NCBI Sequence Read Archive under accession identifier BioProject PRJNA478429/SUB4218081 (https:// www.ncbi.nlm.nih.gov/bioproject/)—Bio Samples SUB4223004, SUB4242917, and SUB4247405 for HB2, JB1, and NK4 sequences, respectively.

\section{DISCUSSION}

Robust linkage maps are essential for mapping QTL intervals associated with complex phenotypic traits. The first genetic linkage map for an interspecific $C$. dentata $\times C$. mollissima $\mathrm{F}_{2}$ population was constructed and used for mapping resistance to $C$. parasitica and six morphological traits in 1997 (Kubisiak et al. 1997). Anonymous genetic markers on this map (e.g., restriction fragment length polymorphisms, random amplified polymorphic DNA, and isozymes) were specific to parental genotypes and were not transferable to other crosses. Because of efficient transferability across different genetic backgrounds, transcriptome-derived SSRs and SNPs advanced significantly the development of genetic maps suitable for comparative genomic analysis, QTL analyses, and candidate gene discovery within QTL intervals (Kubisiak et al. 2013; Staton et al. 2015). In this study, sequence-based genotyping provided additional (10-fold) increase in the number of markers available for linkage analysis; > 7,000 sequence-based SNPs were mapped on eight recombinant genetic maps, with average length and marker density similar to those for the interspecific C. mollissima $\times$ C. dentata $\mathrm{F}_{2}$ map by Kubisiak et al. (2013). Other

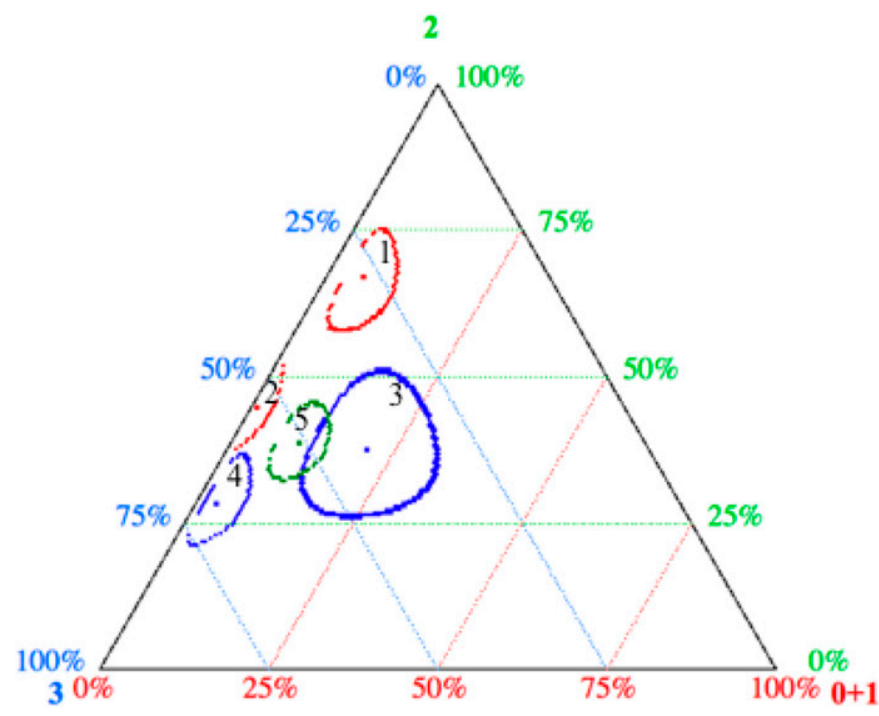

Fig. 2. Segregation of hybrid chestnut families for resistance to Phytophthora cinnamomi. Data for three phenotypic categories with Wilson confidence intervals are plotted for the hybrid crosses 1, HB2-2013, 2, HB2-2014, 3, JB12013, 4, JB1-2014, and 5, NK4-2014. Phenotypic symptom severity classes are labeled on the vertices and color coded on the sides of the triangle: red, combined classes $0+1$; green, class 2 ; and blue, class 3 . Colored points represent proportional phenotypic data, whereas colored circles represent the error region of $95 \%$ lower and upper confidence limits. The diagram was drawn using the online resource at http://burdine-stat.princeton.edu/. 
interspecific Castanea maps were of similar length (Kubisiak et al. 1997; Santos et al. 2017b; Sisco et al. 2005). Noteworthy, genetic maps of $\sim 100$ to $200 \mathrm{cM}$ longer in length were reported for intraspecific crosses in both $C$. mollissima (Kubisiak et al. 2013) and $C$. sativa (Casasoli et al. 2001, 2004). In our case, the stringent criteria $(P \leq 0.05)$ used for filtering distorted markers may explain the variation in size of LGs in the HB2-2014 and NK4-2014 crosses. The impact of segregation distortion on genetic mapping and size of LGs in plants is well established in the literature (reviewed in XianLiang et al. 2006).

In our study, LGs constructed for four American chestnut parents exhibited the same marker order as that in the Chinese/American $\mathrm{BC}_{1}$ hybrid parents. Therefore, there was no evidence of large genome reorganizations, at least with markers generated from reads aligned against the $C$. mollissima reference genome. The only noticeable disorder was a potential inversion in the putative pericentromeric region of LG_E on the map of JB197, a BC 2 male parent in the JB1 cross. Suppressed recombination in this region (6.6 and $14.0 \mathrm{cM}$ on JB197 and reference maps, respectively) was in agreement with a key genetic effect of inversions in plants and animals (Kirkpatrick 2010; Wellenreuther and Bernatchez 2018).

A significant QTL for resistance to $P$. cinnamomi on LG_E was initially detected using a low-density genetic map for $\mathrm{BC}_{1}$ cross AdairKY $1 \times$ GL158 derived from hybridization American chestnut tree with an $\mathrm{F}_{1}$ interspecific hybrid $C$. dentata $\times C$. mollissima 'Nanking'. This cross, which had only a limited number of individuals, was phenotyped using a protocol that differed from the one used in our study. A strong QTL was detected at the bottom of LG_E in the map of the GL158 parent carrying the resistance (Kubisiak 2010; Zhebentyayeva et al. 2014). In preliminary studies to justify a more comprehensive high-throughput, genome-wide genotyping strategy, we also constructed local genetic maps using a small reference set of the EST SSRs (Kubisiak et al. 2013) and confirmed QTL signals in the middle and the end of the LG_E in four hybrid populations: NK1-2012, NK2-2012, HB2-2011, and HB2-2012 (Zhebentyayeva 2017). Markers most associated with QTLs in these crosses were localized within QTL intervals qPcE.2 and $\mathrm{qPcE} .3$. Thus, these preliminary QTL mapping results generated with low-density genetic maps are in agreement with those reported here.

Taking advantage of transcriptome-based SSRs transferable across Castanea species, we also compared our QTL mapping results with those in progeny from an $\mathrm{F}_{1}$ interspecific $C$. sativa $\times$ $C$. crenata cross that were phenotyped with an excised shoot inoculation protocol (Santos et al. 2017b). In spite of differences in phenotyping methods (i.e., root rot severity scores in our study and rate of lesion progression on shoots in Santos et al. [2017b]), two QTLs in the $C$. sativa $\times C$. crenata cross overlapped with QTLs reported here on LG_E (within the qPcE.1 interval) and on LG_K. Because there were only a few bridging markers between our maps and the map of Santos et al. (2017b), QTL Pc_K1 in C. sativa $\times$ C. crenata cross was extrapolated to a broad interval covering both the qPcK.1 and qPcK.2 intervals in HB2-2013 and HB2-2014 progeny, respectively. Collectively, these data support the initial observation of a major QTL(s) for resistance to P. cinnamomi on LG_E in hybrid BC families with either 'Mahogany' or 'Nanking' as the original Chinese progenitor. Therefore, based on integrated QTL analysis of LG_E, we conclude that there are three QTLs for resistance to $P$. cinnamomi in the upper, middle, and lower regions of this LG.

One of the main objectives of this study was to determine the genetic architecture of resistance to $P$. cinnamomi in Chinese chestnut, leveraging three available Chinese $\times$ American $\mathrm{BC}$ populations initiated with two Chinese chestnut sources of resistance: 'Nanking' and 'Mahogany'. The results reported here show that genetic control of resistance to $P$. cinnamomi in chestnut is more complicated than that of a one-dominant-gene model describing a simple Mendelian 1:1 ratio for proportion of dead and alive plants in Table 3 . The phenotypic performance of seedlings, as judged by the proportion of plants within a cross assigned to different phenotypic classes, varied from year to year as shown on the ternary plot (Fig. 2), except in the NK4-2014 and JB1-2013 crosses. Additionally, the strength of a QTL varied by year in data on progeny from the same cross but phenotyped in different years. This was especially evident for the differing LOD scores between HB2-2013 and HB2-2014 (Table 4). It is likely that environmental

TABLE 4. Quantitative trait loci (QTLs) associated with resistance to Phytophthora cinnamomi in progenies from crosses HB2, JB1, and NK4 phenotyped in 2013 and 2014

\begin{tabular}{|c|c|c|c|c|c|c|}
\hline Cross-year ${ }^{\mathrm{a}}$ and map designation & QTL $^{b}$ & Cofactor $^{\mathrm{c}}$ & Position (cM) & $\operatorname{LOD}^{\mathrm{d}}$ & EPVe $(\%)$ & Effect $^{\mathrm{f}}$ \\
\hline \multicolumn{7}{|l|}{ HB2-2013 } \\
\hline KY115-2013 & qPcE.1-H2013 & h25723 & 21.9 & 2.4 & 6.3 & -0.14 \\
\hline KY115-2013 & qPcE.2-H2013 & h54539 & 32.5 & 2.1 & 6.1 & -0.14 \\
\hline \multicolumn{7}{|l|}{ HB2-2014 } \\
\hline KY115-2014 & qPcA.1-H2014 & hb52208 & 23.4 & 3.3 & 5.1 & 0.12 \\
\hline KY115-2014 & qPcE.2-H2014 & hb54410 & 18.2 & 4 & 6.2 & 0.13 \\
\hline KY115-2014 & qPcK.1-H2014 & hb7814 & 19.1 & 5.2 & 9.3 & 0.16 \\
\hline \multicolumn{7}{|l|}{ JB1-2013 } \\
\hline JB197-2013, 2014 & qPcE.2-J2013 & jb79599 & 45.6 & 8.7 & 39.1 & -0.52 \\
\hline JB197-2013, 2014 & qPcE.3-J2013 & jb32342 & 54 & 16.9 & 61.7 & -0.66 \\
\hline \multicolumn{7}{|l|}{ JB1-2014 } \\
\hline JB197-2013, 2014 & qPcE.1-J2014 & jb43327 & 23.2 & 2.8 & 6.7 & -0.15 \\
\hline JB197-2013, 2014 & qPcE.2-J2014 & jb18453 & 45.2 & 7.8 & 17.8 & -0.24 \\
\hline JB197-2013, 2014 & qPcE.3-J2014 & jb13258 & 54.6 & 12.1 & 26.2 & -0.29 \\
\hline
\end{tabular}

a Designation of a specific cross and the year that progeny were phenotyped.

b QTLs are named in their order on linkage groups.

c Most associated markers within QTLs for resistance to P. cinnamomi.

${ }^{\mathrm{d}}$ Logarithm of odds (LOD) score.

e Percentage of explained phenotypic variance (EPV) for the trait by marker.

${ }^{f}$ Estimated additive effect. 
factors had a significant impact on the survival of chestnut progeny, which was reflected in the QTL mapping results. Lower QTL signals and higher survival rates in the progeny from the HB2 cross were recorded in 2013 compared with those in 2014 . One possibility for this variation is that the most susceptible plants (class 3) may have been misclassified as partially resistant in 2013 if weather conditions were less conductive to disease development than in 2014. In fact, we have observed that previously scored resistant progeny (classes 1 or 2) continued to die, although at a diminishing proportion, over the course of two additional growing seasons when seedlings were planted in the field (J. B. James, data not presented). Nevertheless, the consistent QTL results from JB1-2013 and JB1-2014, phenotyped in different years in different geographical locations and using different isolates of $P$. cinnamomi as inoculum, demonstrate that environmental effects did not significantly impact QTL detection.

In this communication, we provide the first comprehensive investigation of the genetics of resistance to $P$. cinnamomi in C. mollissima $\times$ C. dentata progeny. Comparing the genetics of our $P$. cinnamomi resistance in chestnut with Phytophthora resistance in other crops species, we find some intriguing parallels. In soybean, a series of resistance to $P$. sojae (Rps) genes has been previously shown to confer two distinct types of host resistance: race-specific resistance conditioned by a single dominant $R p s$ gene and partial resistance conferred by multiple genes acting together (Sugimoto et al. 2012). So far, 27 Rps genes were described in soybean, of which several of them are located about $10 \mathrm{cM}$ apart (Sahoo et al. 2017; Sandhu et al. 2005; Stasko et al. 2016). On a chromosomal scale, this resembles the location of our three QTLs on LG_E, which are $\sim 10 \mathrm{cM}$ apart. In tobacco (Vontimitta and Lewis 2012 ), at least six QTLs, including two major loci, control resistance to $P$. nicotianae. The genetic architectures of resistance in tobacco and soybean fit into a model with race-specific resistance conditioned by one dominant gene and quantitatively inherited partial resistance conferred by multiple genes. From our results and by analogy to these other systems, we hypothesize that resistance to $P$. cinnamomi in chestnut may also be under control of one or two dominant major-effect genes and minor-effect QTLs that are dependent on environment.

Limited information is available about global genetic diversity of $P$. cinnamomi. However, most of these studies agree that populations of $P$. cinnamomi from a variety of crops and ecosystems have relatively low genetic diversity compared with that in other species of the genus Phytophthora (Beaulieu et al. 2017; Duan et al. 2008; Eggers et al. 2012; Linde et al. 1999; Pagliaccia et al. 2013). In our experiment, the JB1-2013 cross was inoculated with a $P$. cinnamomi isolate recovered from a different location than those isolates used in the JB1-2014 and other crosses. In spite of using these different isolates (from Tennessee and South Carolina, respectively), two strong effect QTLs on LG_E detected in

\section{composite-LG_E}

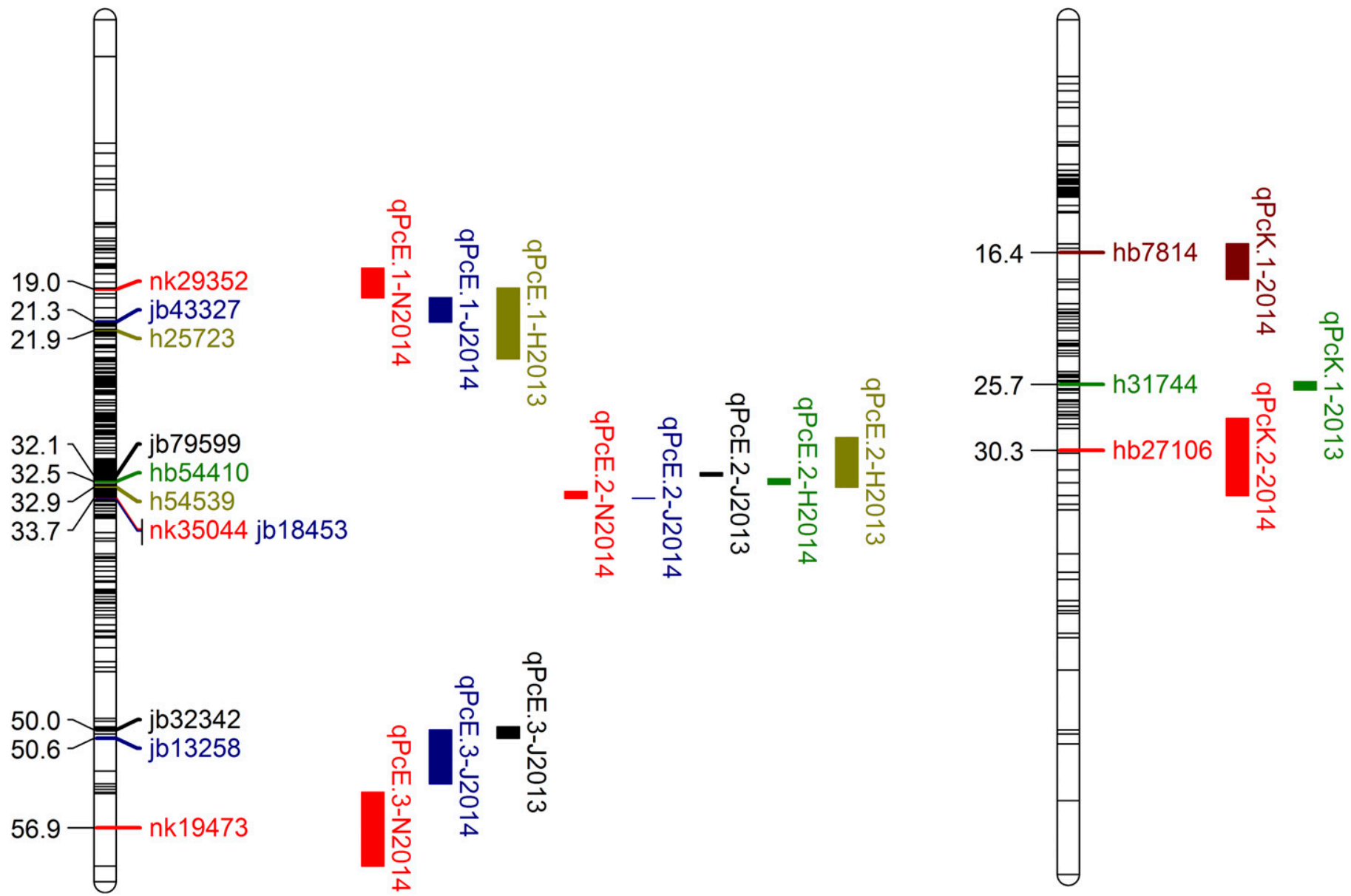

Fig. 3. Colocalization of quantitative trait loci (QTLs) for resistance to Phytophthora cinnamomi in multiple crosses on composite maps of two linkage groups (LGs) LG_E and LG_K, which have 424 and 121 single-nucleotide polymorphism markers, respectively. Parental maps for crosses HB2, JB1, and NK4 were merged using LPmerge software in R statistical language (Endelman and Plomion 2014). QTLs detected in individual crosses (H-HB2, N-NK4, and J-JB1) are drawn as colored bars along linkage groups using MapChart 3.0 (Voorrips 2002). The most significant markers associated with QTLs and their positioning on composite maps are listed adjacent to the LG and colored the same as the bar depicting the QTL-year designation. 
JB197-2013 and JB197-2014 maps (resistant parent) were mapped to the same intervals on the composite LG_E map. Additional research about virulence of different $P$. cinnamomi isolates will be necessary to validate that these two QTLs are $P$. cinnamomi-isolate independent.

Our current understanding of the molecular mechanisms underlying resistance to root rot caused by Phytophthora species largely comes from a soybean-P. sojae host-pathogen system because several strain-specific genes in soybean were identified and cloned (Dorrance 2018). A diverse group of Rps genes from soybean shared a homology on conserved motifs, such as leucinerich repeats, nucleotide-binding sites, and several other conserved domains. The R genes tend to cluster and, sometimes, they cluster in gene-poor regions of a genome (Gao and Bhattacharyya 2008; Sacco and Moffett 2009). This clustering feature may facilitate the expansion of gene numbers that lead to a generation of new recognition specificities through recombination and positive selection. Suppressed recombination in JB197 in our study may indicate that we are dealing with a similar type of $\mathrm{R}$ genes. Mechanisms involved in partial broad spectrum resistance imply a number of small effect genes coordinately acting to provide more durable defense, at least in a well-studied crop such as soybean (Sugimoto et al. 2012; Zhong et al. 2018). In future work, we will utilize the available genomic resources for $C$. mollissima and $C$. dentata and newly generated RNA-seq data for susceptible and resistant $P$. cinnamomi tissue reactions (work in progress) to establish candidate genes within these QTL intervals for further investigating the mechanism for resistance to $P$. cinnamomi in these chestnut tree species.

\section{ACKNOWLEDGMENTS}

We thank numerous TACF volunteers and several members of the Clemson University Phytophthora Team who participated in this project by pollinating trees in the field; harvesting seeds; and planting, maintaining, and phenotyping seedlings in the field. Special thanks to Thomas Clinton Neel and Inga M. Meadows (Mountain Horticultural Crops Research and Extension Center, North Carolina State University, Mills River, NC) for help with phenotyping of the JB1-2013 cross in Tennessee. Also, we thank Xiaoxia Xia for a modified protocol for constructing restriction site-associated genomic DNA libraries. We are grateful to Jared Westbrook for helpful discussions regarding the results of this study and an anonymous reviewer for insightful comments and suggestions. This is Technical Contribution Number 6736 of the Clemson University Experiment Station.

\section{LITERATURE CITED}

Anagnostakis, S. L. 1992. Measuring resistance of chestnut trees to chestnut blight. Can. J. For. Res. 22:568-571.

Anagnostakis, S. L. 2012. Chestnut breeding in the United States for disease and insect resistance. Plant Dis. 96:1392-1403.

Bai, B., Wang, L., Zhang, Y. J., Lee, M., Rahmadsyah, R., Alfiko, Y., Ye, B. Q., Purwantomo, S., Suwanto, A., Chua, N.-H., and Yue, G. H. 2018. Developing genome-wide SNPs and constructing an ultrahigh-density linkage map in oil palm. Sci. Rep. 8:691.

Beaulieu, J., Ford, B., and Balci, Y. 2017. Genotypic diversity of Phytophthora cinnamomi and $P$. plurivora in Maryland's Nurseries and Mid-Atlantic Forests. Phytopathology 107:769-776.

Burgess, T. I., Scott, J. K., Mcdougall, K. L., Stukely, M. J. C., Crane, C., Dunstan, W. A., Brigg, F., Andjic, V., White, D., Rudman, T., Arentz, F., Ota, N., and St. Hardy, G. E. 2017. Current and projected global distribution of Phytophthora cinnamomi, one of the world's worst plant pathogens. Glob. Change Biol. 23:1661-1674.

Burnham, C. R. 1988. The restoration of the American chestnut. Am. Sci. 76: 478-487.

Cahill, D., Legge, N., Grant, B., and Weste, G. 1989. Cellular and histological changes induced by Phytophthora cinnamomi in a group of plant species ranging from fully susceptible to fully resistant. Phytopathology 79:417-424.

Cahill, D. M., and McComb, J. A. 1992. A comparison of changes in phenylalanine ammonia-lyase activity, lignin and phenolic synthesis in the roots of Eucalyptus calophylla (field resistant) and E. marginata (susceptible) when infected with Phytophthora cinnamomi. Physiol. Mol. Plant Pathol. 40:315-332.

Casasoli, M., Mattioni, C., Cherubini, M., and Villani, F. 2001. A genetic linkage map of European chestnut (Castanea sativa Mill.) based on RAPD, ISSR and isozyme markers. Theor. Appl. Genet. 102:1190-1199.

Casasoli, M., Pot, D., Plomion, C., Monteverdi, M. C., Barreneche, T., Lauteri, M., and Villani, F. 2004. Identification of QTLs affecting adaptive traits in Castanea sativa Mill. Plant Cell Environ. 27:1088-1101.

Catchen, J., Amores, A., Hohenlohe, P., Cresko, W., and Postlethwait, J. 2011. Stacks: Building and genotyping loci de novo from short-read sequences. G3 (Bethesda) 1:171-182.

Churchill, G. A., and Doerge, R. W. 1994. Empirical threshold values for quantitative trait mapping. Genetics 138:963-971.

Clark, M. D., The, S. L., Burkness, E., Moreira, L., Watson, G., Yin, L., Hutchison, W. D., and Luby, J. J. 2018. Quantitative trait loci identified for foliar phylloxera resistance in a hybrid grape population. Aust. J. Grape Wine Res. 24:292-300.

Coelho, A. C., Horta, M., Ebadzad, G., and Cravador, A. 2011. Quercus suberPhytophthora cinnamomi interaction: Hypothetical molecular mechanism model. N. Z. J. Sci. 41S:143-157.

Crandall, B. S., Gravatt, G. F., and Ryan, M. M. 1945. Root disease of Castanea species and some coniferous and broadleaf nursery stocks caused by Phytophthora cinnamomi. Phytopathology 35:162-180.

Davey, J. W., Hohenlohe, P. A., Etter, P. D., Boone, J. Q., Catchen, J. M., and Blaxter, M. L. 2011. Genome-wide genetic marker discovery and genotyping using next-generation sequencing. Nat. Rev. Genet. 12:499-510.

Dempsey, R. W., Merchant, A., and Tausz, M. 2012. Differences in ascorbate and glutathione levels as indicators of resistance and susceptibility in $\mathrm{Eu}$ calyptus trees infected with Phytophthora cinnamomi. Tree Physiol. 32: 1148-1160.

Desnoues, E., Norelli, J. L., Aldwinckle, H. S., Wisniewski, M. E., Evans, K. M., Malnoy, M., and Khan, A. 2018. Identification of novel strainspecific and environment-dependent minor QTLs linked to fire blight resistance in apples. Plant Mol. Biol. Report. 36:247-256.

Dorrance, E. E. 2018. Oomycete and fungal pathogens of soybean. Pages 3-25 in: Achieving Sustainable Cultivation of Soybeans, Vol. 2. H. Nguyen, ed. Burleigh Dodds Science Publishing, London, United Kingdom.

Duan, C.-H., Riley, M. B., and Jeffers, S. N. 2008. Characterization of Phytophthora cinnamomi populations from ornamental plants in South Carolina, USA. Arch. Phytopathol. Plant Prot. 41:14-30.

Ebadzad, G., and Cravador, A. 2014. Quantitative RT-PCR analysis of differentially expressed genes in Quercus suber in response to Phytophthora cinnamomi infection. Springerplus 3:613.

Eggers, J. E., Balci, Y., and MacDonald, W. L. 2012. Variation among Phytophthora cinnamomi isolates from oak forest soils in the eastern United States. Plant Dis. 96:1608-1614.

Elshire, R. J., Glaubitz, J. C., Sun, Q., Poland, J. A., Kawamoto, K., Buckler, E. S., and Mitchell, S. E. 2011. A robust, simple genotyping-by- sequencing (GBS) approach for high diversity species. PLoS One 6:e19379.

Endelman, J. B., and Plomion, C. 2014. LPmerge: An R package for merging genetic maps by linear programming. Bioinformatics 30:1623-1624.

Engelbrecht, J., and van den Berg, N. 2013. Expression of defence-related genes against Phytophthora cinnamomi in five avocado rootstocks. S. Afr. J. Sci. 109:1-8.

Erwin, D. C., and Ribeiro, O. K. 1996. Phytophthora Diseases Worldwide. American Phytopathological Society, St. Paul, MN.

Freinkel, S. 2007. American Chestnut: The Life, Death, and Rebirth of a Perfect Tree. University of California Press, Berkeley, CA.

Ganal, M. W., Wieseke, R., Luerssen, H., Durstewitz, G., Graner, E.-M., Plieske, J., and Polley, A. 2014. High-throughput SNP profiling of genetic resources in crop plants using genotyping arrays. Pages 113-130 in: Genomics of Plant Genetic Resources. Volume 1. Managing, Sequencing and Mining Genetic Resources. R. Tuberosa, A. Graner, and E. Frison E., eds. Springer, New York, NY

Gao, H., and Bhattacharyya, M. K. 2008. The soybean-Phytophthora resistance locus Rps1-k encompasses coiled coil-nucleotide bindingleucine rich repeat-like genes and repetitive sequences. BMC Plant Biol. 8:29-33.

Grattapaglia, D., and Sederoff, R. 1994. Genetic linkage maps of Eucalyptus grandis and Eucalyptus urophylla using a pseudo-testcross: Mapping strategy and RAPD markers. Genetics 137:1121-1137.

Graves, A. H. 1950. Relative blight resistance in species and hybrids of Castanea. Phytopathology 40:1125-1131.

Hardham, A. R., and Blackman, L. M. 2018. Phytophthora cinnamomi. Mol. Plant Pathol. 19:260-285.

Jacobs, D. F., Dalgleish, H. J., and Nelson, C. D. 2013. A conceptual framework for the restoration of threatened plants: The effective model of American chestnut (Castanea dentata) reintroduction. New Phytol. 197:378-393. 
Jamann, T. M., Balint-Kurti, P. J., and Holland, J. B. 2015. QTL mapping using high-throughput sequencing. Methods Mol. Biol. 1284:257-285.

Jeffers, S. N., James, J. B., and Sisco, P. H. 2009. Screening for resistance to Phytophthora cinnamomi in hybrid seedlings of American chestnut. Pages 188-194 in: Proceedings of the Fourth Meeting of the International Union of Forest Research Organizations (IUFRO) Working Party S07.02.09: Phytophthoras in Forests \& Natural Ecosystems. Gen. Tech. Rep. PSW-GTR221. E. M. Goheen and S. J. Frankel, eds. U.S. Department of Agriculture, Forest Service, Pacific Southwest Research Station. Albany, CA.

Jung, T., Perez-Sierra, A., Duran, A., Horta Jung, M., Balci, Y., and Scanu, B. 2018. Canker and decline diseases caused by soil- and airborne Phytophthora species in forests and woodlands. Persoonia 40:182-220.

Kirkpatrick, M. 2010. How and why chromosome inversions evolve. PLoS Biol. 8:e1000501.

Konar, A., Choudhury, O., Bullis, R., Fiedler, L., Kruser, J. M., Stephens, M. T., Gailing, O., Schlarbaum, S., Coggeshall, M. V., Staton, M. E., Carlson, J. E., Emrich, S., and Romero-Severson, J. 2017. High-quality genetic mapping with ddRADseq in the non-model tree Quercus rubra. BMC Genomics 18:417.

Kubisiak, T. 2010. NE-1333 Technical Committee Meeting Minutes. https:// ecosystems.psu.edu/research/chestnut/meetings/crees-ne-projects/minutespdfs/2010-research-meeting-minutes

Kubisiak, T. L., Hebard, F. V., Nelson, C. D., Zhang, J., Bernatzky, R., Huang, H., Anagnostakis, S. L., and Doudrick, R. L. 1997. Molecular mapping of resistance to blight in an interspecific cross in the genus Castanea. Phytopathology 87:751-759.

Kubisiak, T. L., Nelson, C. D., Staton, M. E., Zhebentyayeva, T., Smith, C., Olukolu, B. A., Fang, G.-C., Hebard, F. V., Anagnostakis, S., Wheeler, N., Sisco, P. H., Abbott, A. G., and Sederoff, R. R. 2013. A transcriptome-based genetic map of Chinese chestnut (Castanea mollissima) and identification of regions of segmental homology with peach (Prunus persica). Tree Genet. Genomes 9:557-571.

Linde, C., Drenth, A., and Wingfield, M. J. 1999. Gene and genotypic diversity of Phytophthora cinnamomi in South Africa and Australia revealed by DNA polymorphisms. Eur. J. Plant Pathol. 105:667-680.

Mahomed, W., and van den Berg, N. 2011. EST sequencing and gene expression profiling of defence-related genes from Persea americana infected with Phytophthora cinnamomi. BMC Plant Biol. 11:167.

Mousavi, M., Tong, C., Liu, F., Tao, S., Wu, J., Li, H., and Shi, J. 2016. De novo SNP discovery and genetic linkage mapping in poplar using restriction site associated DNA and whole-genome sequencing technologies. BMC Genomics 17:656.

Norelli, J. L., Wisniewski, M., Fazio, G., Burchard, E., Gutierrez, B., Levin, E., and Droby, S. 2017. Genotyping-by-sequencing markers facilitate the identification of quantitative trait loci controlling resistance to Penicillium expansum in Malus sieversii. PLoS One 12:e0172949.

Olson, H. A., Jeffers, S. N., Ivors, K. L., Steddom, K. C., Williams-Woodward, J. L., Mmbaga, M. T., Benson, D. M., and Hong, C. X. 2013. Diversity and mefenoxam sensitivity of Phytophthora spp. associated with the ornamental horticulture industry in the southeastern United States. Plant Dis. 97:86-92.

Oßwald, W., Fleischmann, F., Rigling, D., Coelho, A. C., Cravador, A., Diez, J., Dalio, R. J., Horta Jung, M., Pfanz, H., Robin, C., Sipos, G., Solla, A., Cech, T., Chambery, A., Diamandis, S., Hansen, E., Jung, T., Orlikowski, L. B., Parke, J., Prospero, S., and Werres, S. 2014. Strategies of attack and defence in woody plant-Phytophthora interactions. For. Pathol. 44: 169-190.

Pagliaccia, D., Pond, E., McKee, B., and Douhan, G. W. 2013. Population genetic structure of Phytophthora cinnamomi associated with avocado in California and the discovery of a potentially recent introduction of a new clonal lineage. Phytopathology 103:91-97.

Parchman, T. L., Jahner, J. P., Uckele, K. A., Galland, L. M., and Eckert, A. J. 2018. RADseq approaches and applications for forest tree genetics. Tree Genet. Genomes 14:39.

Podger, F. D., Doepel, R. F., and Zentmyer, G. A. 1965. Association of Phytophthora cinnamomi with a disease of Eucalyptus marginata forests in Western Australia. Plant Dis. 49:943-947.

Reeksting, B. J., Coetzer, N., Mahomed, W., Engelbrecht, J., and van den Berg, N. 2014. De novo sequencing, assembly, and analysis of the root transcriptome of Persea americana (Mill.) in response to Phytophthora cinnamomi and flooding. PLoS One 9:e86399.

Russell, E. W. B. 1987. Pre-blight distribution of Castanea dentata (Marsh.). Borkh. Bull. Torrey Bot. Club 114:183-190.

Sacco, M. A., and Moffett, P. 2009. Disease resistance genes: Form and function. Pages 94-141 in: Molecular Plant Microbe Interactions. K. Bouarab, N. Brisson, and F. Daayf, eds. CABI, Wallingford, United Kingdom.

Sahoo, D. K., Abeysekara, N. S., Cianzio, S. R., Robertson, A. E., and Bhattacharyya, M. K. 2017. A novel Phytophthora sojae resistance Rps12 gene mapped to a genomic region that contains several Rps genes. PLoS One 12:e0169950.
Sandhu, D., Schallock, K. G., Rivera-Velez, N., Lundeen, P., Cianzio, S., and Bhattacharyya, M. K. 2005. Soybean Phytophthora resistance gene Rps8 maps closely to the Rps3 region. J. Hered. 96:536-541.

Santos, C., Duarte, S., Tedesco, S., Fevereiro, P., and Costa, R. 2017a. Expression profiling of Castanea genes during resistant and susceptible interactions with the oomycete pathogen Phytophthora cinnamomi reveal possible mechanisms of immunity. Front. Plant Sci. 8:1-12.

Santos, C., Nelson, C. D., Zhebentyayeva, T., Machado, H., Gomes-Laranjo, J., and Costa, R. 2017b. First interspecific genetic linkage map for Castanea sativa $\times$ Castanea crenata revealed QTL for resistance to Phytophthora cinnamomi. PLoS One 12:e0184381.

Santos, C., Zhebentyayeva, T., Serrazina, S., Nelson, C. D., and Costa, R. 2015. Development and characterization of EST-SSR markers for mapping reaction to Phytophthora cinnamomi in Castanea spp. Sci. Hortic. (Amsterdam) 194:181-187.

Schilling, M. P., Wolf, P. G., Duffy, A. M., Rai, H. S., Rowe, C. A., Richardson, B. A., and Mock, K. E. 2014. Genotyping-by-sequencing for Populus population genomics: An assessment of genome sampling patterns and filtering approaches. PLoS One 9:e95292.

Sergeant, E. S. G. 2018. Epitools Epidemiological Calculators. Ausvet Pty Ltd. http://epitools.ausvet.com.au/content.php?page=home

Serrazina, S., Santos, C., Machado, H., Pesquita, C., Vicentini, R., Pais, M. S., Sebastiana, M., and Costa, R. 2015. Castanea root transcriptome in response to Phytophthora cinnamomi challenge. Tree Genet. Genomes 11:6.

Shearer, B. L., Crane, C. E., Barrett, S., and Cochrane, A. 2007. Phytophthora cinnamomi invasion, a major threatening process to conservation of flora diversity in the South-west Botanical Province of Western Australia. Aust. J. Bot. 55:225-238.

Sisco, P., Kubisiak, T., and Casasoli, M. 2005. An improved genetic map for Castanea mollissima/Castanea dentata and its relationship to the genetic map of Castanea sativa. Acta Hortic. 693:491-496.

Stasko, A. K., Wickramasinghe, D., Nauth, B., Acharya, B., Ellis, M., Taylor, C., McHale, L., and Dorrance, A. 2016. High-density mapping of resistance QTL toward Phytophthora sojae, Pythium irregulare, and Fusarium graminearum in the same soybean population. Crop Sci. 56: 2476-2492.

Staton, M., Zhebentyayeva, T., Olukolu, B., Fang, G. C., Nelson, D., Carlson, J. E., and Abbott, A. G. 2015. Substantial genome synteny preservation among woody angiosperm species: Comparative genomics of Chinese chestnut (Castanea mollissima) and plant reference genomes. BMC Genomics 16:744.

Steiner, K. C., Westbrook, J. W., Hebard, F. V., Georgi, L. L., Powell, W. A., and Fitzsimmons, S. F. 2017. Rescue of American chestnut with extra specific genes following its destruction by a naturalized pathogen. New For. 48:317-336.

Stolzy, L. H., Zentmyer, G. A., Klotz, L. J., and Labanauskas, C. K. 1967. Oxygen diffusion, water and Phytophthora cinnamomi in root decay and nutrition of avocados. J. Am. Soc. Hortic. Sci. 90:67-76.

Stukely, M. J. C., and Crane, C. E. 1994. Genetically based resistance of Eucalyptus marginata to Phytophthora cinnamomi. Phytopathology 84: 650-656.

Sugimoto, T., Kato, M., Yoshida, S., Matsumoto, I., Kobayashi, T., Kaga, A., Hajika, M., Yamamoto, R., Watanabe, K., Aino, M., Matoh, T., Walker, D. R., Biggs, A. R., and Ishimoto, M. 2012. Pathogenic diversity of Phytophthora sojae and breeding strategies to develop Phytophthora-resistant soybeans. Breed. Sci. 61:511-522.

Tainter, F. H., O’Brien, J. G., Hernández, A., Orozco, F., and Rebolledo, O. 2000. Phytophthora cinnamomi as a cause of oak mortality in the state of Colima, Mexico. Plant Dis. 84:394-398.

Teh, S. L., Fresnedo-Ramírez, J., Clark, M. D., Gadoury, D. M., Sun, Q., Cadle-Davidson, L., and Luby, J. J. 2017. Genetic dissection of powdery mildew resistance in interspecific half-sib grapevine families using SNPbased maps. Mol. Breed. 37:1.

Van Ooijen, J. W. 2006. JoinMap, Software for the Calculation of Genetic Linkage Maps, Version 4. Kyazma BV, Wageningen, The Netherlands.

Van Ooijen, J. W. 2009. MapQTL Version 6.0, Software for the Mapping of Quantitative Trait Loci in Experimental Populations of Diploid Species. Kyazma BV, Wageningen, The Netherlands.

Vontimitta, V., and Lewis, R. S. 2012. Mapping of quantitative trait loci affecting resistance to Phytophthora nicotianae in tobacco (Nicotiana tabacum L.) line Beinhart-1000. Mol. Breed. 29:89-98.

Voorrips, R. E. 2002. MapChart: Software for the graphical presentation of linkage maps and QTLs. J. Hered. 93:77-78.

Wager, V. A. 1942. Phytophthora cinnamomi and wet soil in relation to the dying-back of avocado trees. Hilgardia 14:517-532.

Wellenreuther, M., and Bernatchez, L. 2018. Eco-evolutionary genomics of chromosomal inversions. Trends Ecol. Evol. 33:427-440.

Westbrook, J. W., James, J. B., Sisco, P. H., Frampton, J., Lucas, S., and Jeffers, S. N. 2019. Resistance to Phytophthora cinnamomi in American 
chestnut (Castanea dentata) backcross populations that descended from two Chinese chestnut (Castanea mollissima) sources of resistance. Plant Dis. doi:10.1094/PDIS-11-18-1976-RE

Wu, T. D., and Nacu, S. 2010. Fast and SNP-tolerant detection of complex variants and splicing in short reads. Bioinformatics 26:873-881.

Xian-Liang, S., Xue-Zhen, S., and Tian-Zhen, Z. 2006. Segregation distortion and its effect on genetic mapping in plants. Chin. J. Agric. Biotechnol. 3: 163-169.

Xu, B., Feng, X., and Burdine, R. D. 2010. Categorical data analysis in experimental biology. Dev. Biol. 348:3-11.

Zentmyer, G. A. 1980. Phytophthora cinnamomi and the Diseases It Causes. Monograph No. 10. American Phytopathology Society, St. Paul, MN.

Zhebentyayeva, T. 2017. An Update on QTL Mapping of Resistance to $P$. cinnamomi in Biparental American $\times$ Chinese Chestnut Crosses. NE-1333 Technical Committee Meeting Minutes. https://ecosystems.psu.edu/research/chestnut/meetings/crees-ne-projects/minutes-pdfs/2017-researchmeeting-minutes
Zhebentyayeva, T., Shankar, V., Scorza, R., Callahan, A., Ravelonandro, M., Castro, S., DeJong, T., Saski, C. A., and Dardick, C. 2019. Genetic characterization of world-wide Prunus domestica (plum) germplasm using sequence-based genotyping. Hortic. Res. 6:12.

Zhebentyayeva, T., Staton, M., Olukolu, B., Chandra, A., Jeffers, S., James, J., Sisco, P., Hebard, F., Georgi, L., Nelson, C. D., and Abbott, A. G. 2014. Genetic and genomic resources for mapping resistance to root rot disease (Phytophthora cinnamomi) in chestnut. Acta Hortic. 1019:263-270.

Zhigunov, A. V., Ulianich, P. S., Lebedeva, M. V., Chang, P. L., Nuzhdin, S. V., and Potokina, E. K. 2017. Development of $F_{1}$ hybrid population and the high-density linkage map for European aspen (Populus tremula L.) using RADseq technology. BMC Plant Biol.: 180.

Zhong, C., Sun, S., Li, Y., Duan, C., and Zhu, Z. 2018. Next-generation sequencing to identify candidate genes and develop diagnostic markers for a novel Phytophthora resistance gene, RpsHC18, in soybean. Theor. Appl. Genet. 131:525-538. 